\title{
Artificial Intelligence Technologies in Higher Education Institutions: a Model of Adaptive Education
}

\author{
Alexey V. Bataev \\ Graduate school of public and financial management \\ Peter the Great St.Petersburg Polytechnic University \\ St. Petersburg, Russia \\ bat_a68@mail.ru
}

\author{
Ksenia I. Bataeva \\ Orient Express Bank \\ St. Petersburg, Russia \\ Ksenia_88_08@bk.ru
}

\begin{abstract}
The world economic system is on the verge of the fourth technological order, the transition to which is caused by the widespread introduction of information and communication technologies in all areas of development. The introduction of innovative digital technologies has led to the digitalization of the economic sphere and the formation of a new economic sector the digital economy, which is the driver of the development of the entire economic system today. One of the main areas of the digital economy is using cloud computing, big data, the implementation of cyber-physical systems, as well as the development of artificial intelligence systems. Innovative approaches in economic development are modern challenges for the entire education system, requiring the training of highly qualified specialists who can solve problems arising at the present stage of development. The development of innovative digital technologies not only transforms the entire system of economic relations but also allows formatting new innovative approaches in education, opening up new prospects for development. The approaches and possibilities of using artificial intelligence systems in the higher education system are analyzed in the paper, in connection with which a large-scale study of the global artificial intelligence market is carried out: its key parameters in the field of finance, the pace of development are determined; the main leaders in this field are identified. The directions of the application of artificial intelligence systems were analyzed in this study, within which it was determined that the field of education is one of the promising areas of application of these technologies. In education, adaptive student learning is one of the most popular sectors for the introduction of the technologies under consideration: it allows setting an individual learning path for each individual, based on the analysis and processing of training data for each student using artificial intelligence systems. In this regard, the conceptual model of an adaptive learning system using these technologies is considered and analyzed in the article. On the basis of the received information, it would allow to raise the quality of training of specialists in higher educational institutions to a new level.
\end{abstract}

Keywords - information technology management; educational process; systems with artificial intelligence; adaptive learning; modeling; higher education institutions

\section{INTRODUCTION}

One of the drivers of economic development is the technology of artificial intelligence, which allows to provide a solution to many problems related not just to the automation of technological processes, but also to the solution of problems, which only the person could perform.

Today, artificial intelligence systems solve complex tasks in management, creating unmanned production, while the control of all technological processes is assigned to these systems. The introduction of artificial intelligence systems takes place not only in production but also in the financial sector. For example, today attempts are made to exploit such technologies to analyze the cash flows of companies and, based on that, study prospects for development are determined in one direction or another. It can be recalled the announced program of introducing artificial intelligence systems into the work of the Russian bank - Sberbank, which involves replacing more than three thousand lawyers providing legal assistance to clients of a financial institution. Besides, service robots with elements of artificial intelligence are part of our daily lives, providing comfortable living conditions for each person.

In the future, the proposed concept of Industry 4.0 involves the formation of single information and cybernetic environment using artificial intelligence technologies for the existence of a single person, capable of providing comfortable living conditions with his or her requirements and wishes. [1-3]

Today, using artificial intelligence is included in the sphere of education. The first systems are created on the basis of these technologies in the field of proctoring when machines monitor the students' passing tests and tasks when they are passed in an electronic environment by using face recognition algorithms.

One of the areas in education is using artificial intelligence technologies in adaptive learning, the use of which allows determining the possibilities of forming an individual educational trajectory for each student. In this area, the study is just beginning to form, so the analysis of the problem is quite relevant and requires close consideration. [4] 


\section{KEY RESEARCH FINDINGS}

\section{A. Definition and directions of development of artificial intelligence technologies}

The development of artificial intelligence systems began in the $60-70$ s of the last century with the development of the first neural networks, heuristic programming methods and the development of situation control methods for large systems.

Currently, there is no unique definition of artificial intelligence. Artificial intelligence is interpreted on the basis of different approaches in different areas of modern science.

Artificial intelligence is an area of information technology from the standpoint of the information approach, the main task of which is the development of intelligent computer systems that can solve problems that were traditionally solved with the help of the human mind, for example, understanding the language, reasoning, solving problems.

At present, several directions in the development of artificial intelligence technologies are distinguished:

Neural networks are a mathematical model, as well as its hardware and software implementation, created in the image and likeness of biological neural networks;

An expert system is a computer system capable of replacing an expert person in various fields on the basis of knowledge base technologies and relevant algorithms;

A natural language processing system is an automatic information system that works with natural language to communicate with the user;

Fuzzy sets are the basic concept of fuzzy logic, in which instead of two values zero and one, the entire range is considered $[0 ; 1]$;

Evolutionary methods and genetic algorithms are heuristic algorithms used for optimization problems, which are based on mechanisms similar to natural selection in nature;

A knowledge extraction system is a new innovative technology for extracting and processing large amounts of information obtained from global computer networks. [2], [5]

\section{B. Evaluation of the global market of artificial intelligence}

Artificial intelligence technologies are one of the drivers of not only the digital economy but also the entire economy as a whole. In 2025, the market for artificial intelligence would reach $\$ 103.7$ billion (Fig. 1). [1], [4-6]

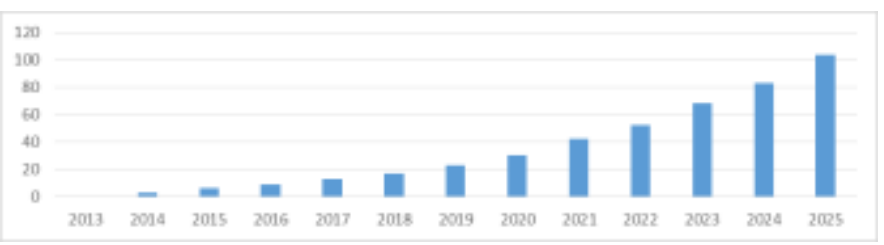

Fig. 1. The dynamics of the market for artificial intelligence systems, billions of dollars
The average annual growth rate of the global artificial intelligence market is about $30 \%$, which is five times higher than the growth rate of the entire IT market.

One of the main areas of application of artificial intelligence is its use in video surveillance systems, which is explained by the achievement in facial recognition using technical vision. The volume exceeds three billion dollars in this area (Fig. 2). [3], [5-8]

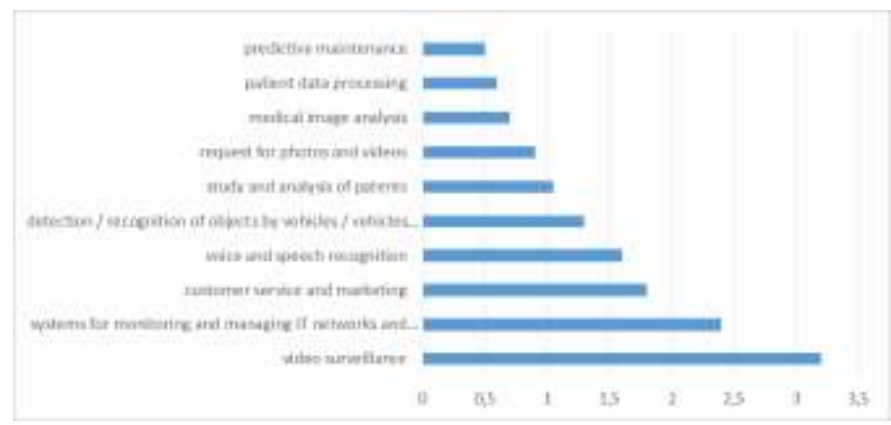

Fig. 2. The main directions of applying artificial intelligence, billions of dollars

One of the leaders in the application of artificial intelligence systems is the United States; its transaction volume exceeds \$ 6.4 billion (Fig. 3). [9, 10]

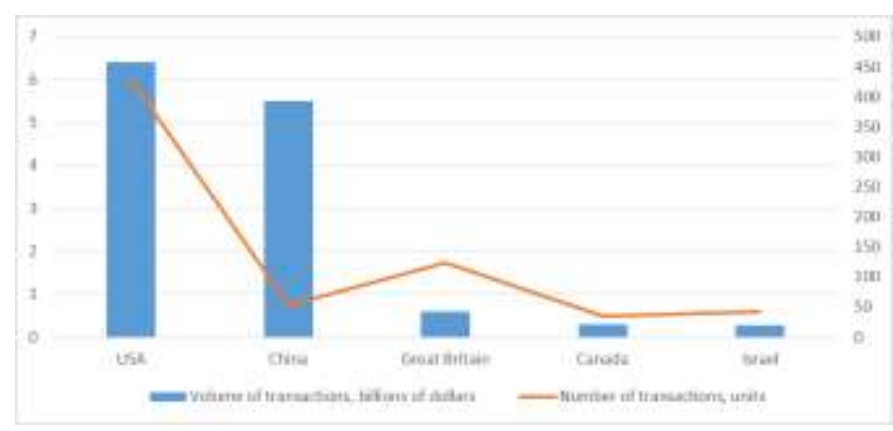

Fig. 3. Leaders of the global artificial intelligence market in 2018

The volume of the Russian artificial intelligence market in 2018 was about $\$ 20$ million, which amounted to about $0.11 \%$ of the global market. In 2020, this indicator should increase to $0.8 \%$.

\section{Analysis of using artificial intelligence in education}

Education is one of the promising areas for the use of artificial intelligence systems. It is possible to obtain the best indicators of increasing factor productivity through the introduction of these technologies. The education sector is among the five leaders in the ranking of promising areas (Fig. 4). [11] 


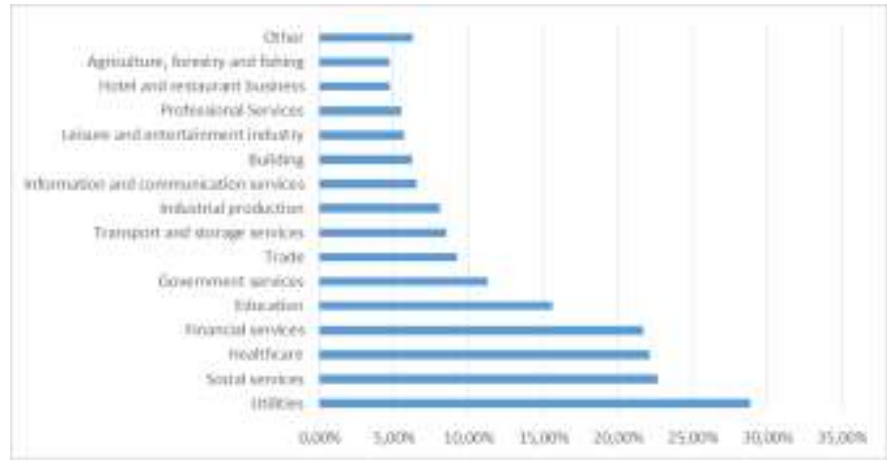

Fig. 4. Rating of industries in terms of increasing factor productivity through the introduction of artificial intelligence, percent

The global market for artificial intelligence in education would reach \$ 3.3 billion in 2025 (Fig. 5). [3], [12].

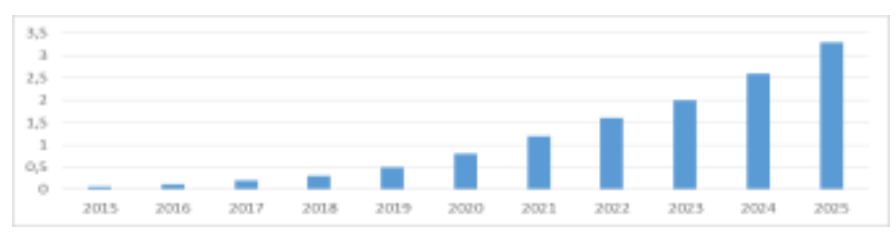

Fig. 5. Dynamics of the global market of artificial intelligence systems in education, billions of dollars

The main direction of the use of artificial intelligence in the field of education is proctoring - a system of remote monitoring of the behavior of the subject during the verification tests (Fig. 6). [13,14]

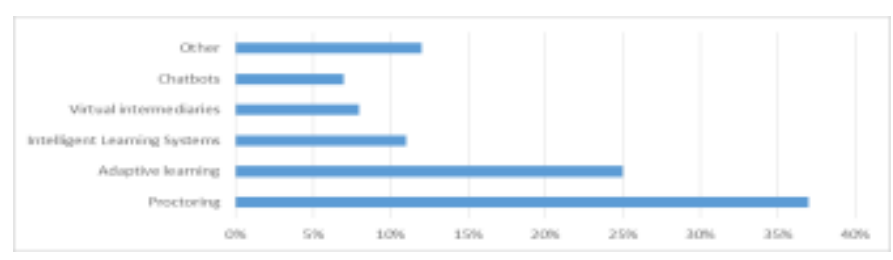

Fig. 6. The main directions of the use of artificial intelligence in education, percent

\section{The model for the formation of adaptive learning based on artificial intelligence technologies}

Today, artificial intelligence is the basis of innovative technologies that are beginning to form "smart manufacturing", create "smart cities" and, accordingly, transform the sphere of education. More than a dozen years have been talking about the possibilities of using artificial intelligence technologies in education.

The basis of artificial intelligence in education is the main goal to make computationally accurate and explicit forms of educational, psychological and social knowledge that often remains implicit, that is, to present this knowledge in a formalized way, in order to analyze the results using computer programs and, based on the study, obtain an appropriate training model.
One of the areas of artificial intelligence is the possibility of forming adaptive learning environments that allow determining the individual trajectory of the student based on the analysis.

An adaptive learning environment is a digital one that adapts learning approaches and materials and explores the opportunities and needs of individual students.

The basis of artificial intelligence is the models and the modeling process. These models are real processes in the form of computer programs, on the basis of which one can make the corresponding calculations and forecasts.

Using artificial intelligence in education has to be based on three basic approaches:

- $\quad$ training process description (pedagogical model);

- description of the discipline (domain model);

- description of the learner (learner model). [6], [8], [11]

Each suggested model is a set of specific components, presented in Table 1 .

TABLE I. THE BASIC MODELS THAT ARE BASED ON ARTIFICIAL INTELLIGENCE IN EDUCATION

\begin{tabular}{|c|c|c|}
\hline $\begin{array}{l}\text { Types of } \\
\text { models }\end{array}$ & Model basis & Model components \\
\hline \multirow[t]{3}{*}{$\begin{array}{l}\text { Pedagogical } \\
\text { model }\end{array}$} & \multirow[t]{3}{*}{$\begin{array}{l}\text { Knowledge and } \\
\text { teaching } \\
\text { experience }\end{array}$} & $\begin{array}{l}\text { "Productive failure" (allows } \\
\text { students to research the concept and } \\
\text { make mistakes before showing the } \\
\text { "correct" answer) }\end{array}$ \\
\hline & & $\begin{array}{l}\text { Feedback (questions, tips) caused } \\
\text { by the student's actions, which is } \\
\text { designed to help the student } \\
\text { improve their learning }\end{array}$ \\
\hline & & $\begin{array}{l}\text { Assessment for determining the } \\
\text { quality of the acquired knowledge }\end{array}$ \\
\hline \multirow[t]{3}{*}{ Domain model } & \multirow{3}{*}{$\begin{array}{l}\text { Knowledge of } \\
\text { the subject under } \\
\text { study (subject } \\
\text { examination) }\end{array}$} & Subject structure \\
\hline & & $\begin{array}{l}\text { Filling and content sections of the } \\
\text { discipline }\end{array}$ \\
\hline & & Subject approaches \\
\hline \multirow[t]{3}{*}{ Learner model } & \multirow[t]{3}{*}{$\begin{array}{l}\text { The student's } \\
\text { knowledge }\end{array}$} & $\begin{array}{l}\text { Previous achievements and } \\
\text { problems of studying an individual } \\
\text { student }\end{array}$ \\
\hline & & Student's emotional state \\
\hline & & $\begin{array}{l}\text { The student's involvement in the } \\
\text { learning process. For example, } \\
\text { time-on-task, the time to complete } \\
\text { the task, which is considered one of } \\
\text { the most important factors affecting } \\
\text { student learning and academic } \\
\text { performance, can be defined as the } \\
\text { amount of time the group spends in } \\
\text { quality training }\end{array}$ \\
\hline
\end{tabular}

Let us imagine a model of adaptive learning based on artificial intelligence technologies, the structure of which has the following form (Fig. 7). [2], [12], [14] 


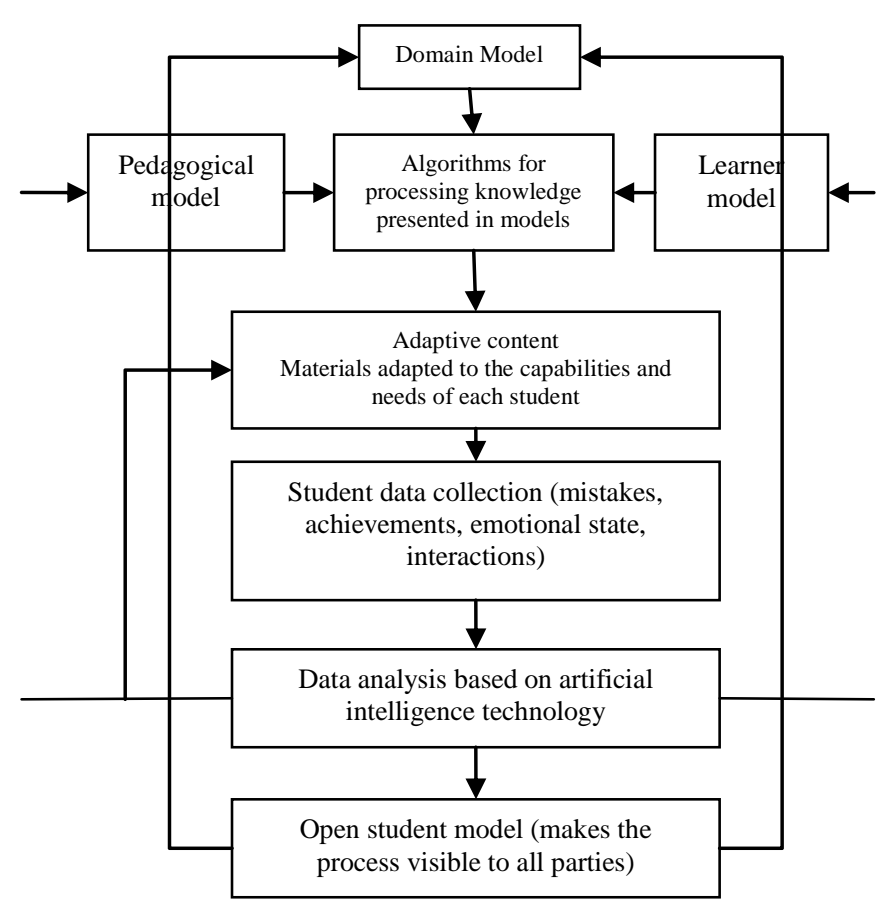

Fig. 7. The structure of the model of adaptive learning based on artificial intelligence technologies

This structure is based on the three basic models described above. Algorithms based on artificial intelligence systems provide content for a single student. In the learning process, the system handles the process of obtaining knowledge in the form of analysis of achievements, mistakes, emotional state of the student. Based on the collected information, a process of analysis of all the parameters of the learning process, on the basis of which self-training and improvement of the system.

The adaptive learning system based on the analysis of a large amount of information and artificial intelligence technologies can provide an individual education path for an individual student in each subject, taking into account his or her capabilities and abilities.

\section{CONCLUSIONS}

The development of the modern world is based on the mass introduction of information and communication technologies, which allow for a new qualitative leap in the development of the entire infrastructure surrounding a person, while the transformation would take place for a single individual. Innovative technologies in the field of artificial intelligence should provide such an opportunity.

Artificial intelligence systems are the driver of the development of the modern digital economy. The global market for these technologies is expected to reach $\$ 103.7$ billion by 2025 , while the average annual growth rate exceeds the growth rate of the entire IT market by five times.

One of the areas of application of artificial intelligence is the education sector, which, according to the possibilities of increasing factor productivity, closes the top five with an indicator of $15.4 \%$. Moreover, the global market for these technologies in the field of education is expected to exceed $\$ 3.3$ billion by 2025 .

One of the main direction of using artificial intelligence in the field of education is the possibility of adaptive learning, which allows, on the basis of three basic models: the pedagogical model, the learner model and the domain model, using knowledge processing algorithms, to provide adapted content for each individual student, through training artificial intelligence systems based on the analysis and processing of large amounts of information. This will allow building an individualized trajectory of the student on the basis of his or her abilities and capabilities both for studying a particular subject and for the process of forming a specialist in a particular field, thereby moving away from the average approach to training that exists today and does not allow opening everything learner capabilities.

\section{REFERENCES}

[1] Spiro R.J., Bruce B.C., Brewer W.F. Theoretical issues in reading comprehension: Perspectives from cognitive psychology, linguistics, artificial intelligence and education. Routledge, 2017.

[2] $\mathrm{Mu} \mathrm{P}$. Research on Artificial Intelligence Education and Its Value Orientation, 2019.

[3] Lesgold A. M. Learning for the Age of Artificial Intelligence: Eight Education Competences. Routledge, 2019.

[4] Kuporov Y.Y., Avduevskaya E.A., Bogacheva T.V. Investments in human capital: Efficiency of investments in higher education in Russia. Proceedings of the 31st International Business Information Management Association Conference, 2018, pp. 926-940.

[5] Liu M. The Application and Development Research of Artificial Intelligence Education in Wisdom Education Era, 2018.

[6] Barrett M. et al. Using Artificial Intelligence to Enhance Educational Opportunities and Student Services in Higher Education. Inquiry: The Journal of the Virginia Community Colleges, Vol. 22, №. 1, 2019, p. 11.

[7] Konnikov, E., Konnikova, O., Leventsov, V. IT Services market as a driver for the development of the artificial intelligence market IOP Conference Series: Materials Science and Engineering, Vol 497, 2019.

[8] Siau K. Impact of artificial intelligence, robotics, and automation on higher education, 2017.

[9] Aoun J.E. Robot-proof: higher education in the age of artificial intelligence. MIT Press, 2017.

[10] Popenici S. A. D., Kerr S. Exploring the impact of artificial intelligence on teaching and learning in higher education. Research and Practice in Technology Enhanced Learning, Vol. 12, №. 1, 2017, p. 22.

[11] Siau K., Wang W. Building trust in artificial intelligence, machine learning, and robotics. Cutter Business Technology Journal, Vol. 31, №. 2, 2018, pp. 47-53.

[12] Colchester K. et al. A survey of artificial intelligence techniques employed for adaptive educational systems within e-learning platforms. Journal of Artificial Intelligence and Soft Computing Research, Vol. 7, №. 1, 2017, pp. 47-64.

[13] Malevskaia-Malevich, E.D., Leonov, S.A., Denis, Z. Quality management in scientific and educational organizations: Methods and tools. Proceedings of the 31st International Business Information Management Association Conference 2018 pp. 5614-5619

[14] Nagao K. Symbiosis between Humans and Artificial Intelligence. Artificial Intelligence Accelerates Human Learning, Springer, Singapore, 2019, pp. 135-151 